\title{
Ewings Sarcoma of the Kidney: A Rare Entity
}

\author{
Surya Kant Choubey ${ }^{\mathrm{a}, \mathrm{b}}$, Gotam Pipara ${ }^{\mathrm{a}}$, \\ Anurag Kumar
}

\begin{abstract}
Primary Ewings sarcoma (EWS) of the kidney is a very rare tumor and very few cases have been reported till date. We present a case of a young girl presenting to us with flank pain. On evaluation, she was found to have a renal mass. She was explored and a nephrectomy was done. Histopathology was reported as EWS. She was then planned for adjuvant chemotherapy. Primary EWS of the kidney is characterized by an aggressive course and poor prognosis. Hence, while dealing with renal masses in young patients, this entity should always be kept in mind.
\end{abstract}

Keywords: Ewings; Sarcoma; Primitive neuroectodermal tumors; Renal; Renal Ewing sarcoma

\section{Introduction}

Primary Ewings sarcoma (EWS) of the kidney is a rare tumor in adults. It was first described in 1975 by Seemayer and colleagues [1]. Only very few cases of primary EWS have been reported in the literature till date [2-9]. Sources of renal EWS include neural cells that invaginate into the kidney during development. Other authors theorize that embryonic neural crest cells migrate into the kidney and undergo tumorigenesis. The diagnosis of primary renal EWS can be difficult and is based on a combination of electron microscopy, immunohistochemistry (IHC), chromosomal analysis, fluorescence in situ hybridization (FISH) and light microscopy. Here we present a rare case of renal EWS operated by us.

\section{Case Report}

A 17-year-old girl presented to us with right flank pain of 2

\footnotetext{
Manuscript accepted for publication March 22, 2017

aDepartment of Urology, St Johns Medical College and Hospital, Bangalore 560034, Karntaka, India

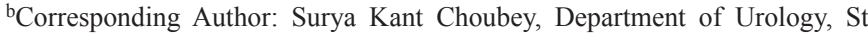
Johns Medical College and Hospital, Bangalore 560034, Karntaka, India. Email: drskchoubeyuro@gmail.com
}

weeks duration. Her medical history was unremarkable. On physical examination, there was a $15 \times 10 \mathrm{~cm}$ hard mass occupying the right hypochondriac, lumbar, epigastric and right iliac fossa region, moving with respiration, bimanually palpable and ballotable. No free fluid was noted in the abdomen on examination (Fig. 1). All the routine blood investigations including serum creatinine were normal. Urine analysis was normal. An ultrasound of the abdomen showed a large heterogeneous solid tumor $(192 \times 108 \mathrm{~mm})$ arising from the right kidney. Few hilar lymph nodes were noted. There was no evidence of liver metastasis/ascitis. A contrast-enhanced computerized tomogram revealed heterogeneously enhancing $12 \times 11 \mathrm{~cm}$ mass occupying the inter-polar region and lower pole of right kidney, posteriorly infiltrating the psoas fascia with multiple hilar lymph nodes (Fig. 2). There was no metastasis to lungs or liver. A USG-guided core biopsy was done which was suggestive of small round cell neoplasm with IHC positive for vimentin and CD99 and negative for cytokeratin, WT1, chromogranin and myogenin suggestive of EWS. Patient was planned for right radical nephrectomy. Intraoperatively, a right renal mass measuring $20 \times 13 \mathrm{~cm}$ was noted arising from the lower pole and infiltrating into the right colon and psoas fascia. Right radical nephrectomy with right hemicolectomy was performed (Fig. 3 ). Histopathology revealed small round to oval nuclei with finely dispersed chromatin and scanty ill-defined cytoplasm with rosette formations. IHC was same as core biopsy (Fig. 4). Postoperative period was uneventful. Postoperatively, she has received adjuvant etoposide-based chemotherapy. Presently she is doing well at the time of this writing.

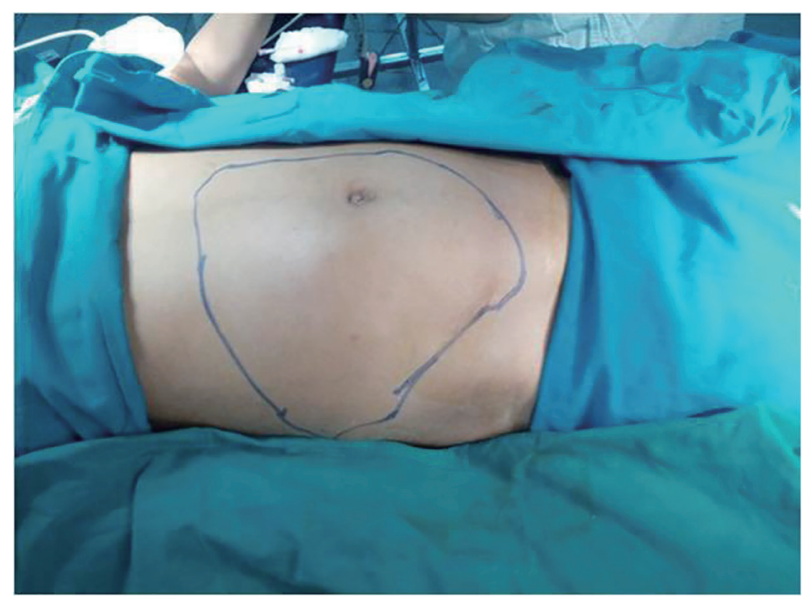

Figure 1. The mass as seen on physical examination. 


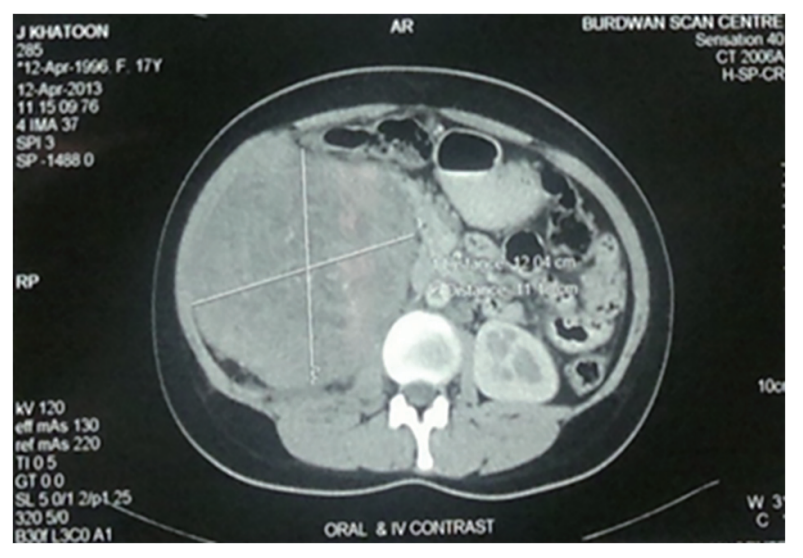

Figure 2. Computed tomographic image of the right kidney.

\section{Discussion}

Primary EWS of the kidney is a rare entity. Sources of renal EWS include neural cells that invaginate into the kidney during development $[2,7]$. Other authors theorize that embryonic neural cells migrate into the kidney and undergo tumorigenesis [1]. Hakky et al [9] in their case report and meta-analysis have described acute flank pain mimicking renal colic as the most common presentation of EWS of the kidney. Our patient also presented with flank pain of short duration which supports their finding.

Histologically, EWS/primitive neuroectodermal tumor is composed of monomorphic small round cells which form Homer right rosettes [10]. Immunohistochemically, the tumor cells are strongly positive for CD99 and leukemia virus integration (FLI)-1. Using a large panel of immunochemistry markers is often essential (cytokeratin, epithelial, membrane antigen, a WT1, synaptophysin, muscle specific actin, desmine, myogenin, LCA and CD45) to exclude other round cell tumors because of important similarities. Thus, the histologist needs to identify and differentiate it from other round cell tumors like rhabdomyosarcoma, Wilms tumor, neuroblastoma, clear cell sarcoma of the kidney, lymphoma, small cell variant of osteosarcoma, desmoplastic small round cell tumor, small

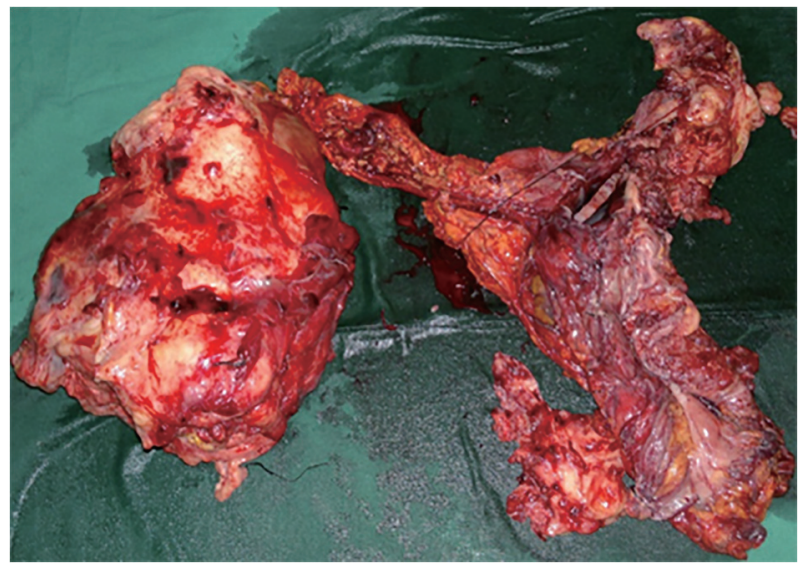

Figure 3. The resected specimen of the kidney and colon.

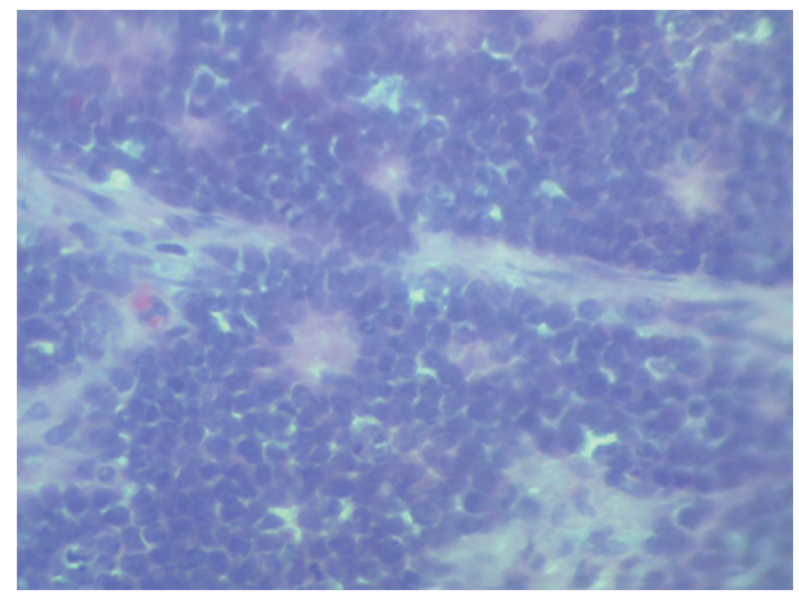

Figure 4. The histopathological image.

cell anaplastic neuroendocrine carcinoma and nephroblastoma [11].

The cytogenetics play an important role in confirming the diagnosis, by localizing the translocation $t(11: 22)(q 24 ; q 12)$ resulting in the production of the EWS/FLI-1 fusion $[12,13]$.

There is no consensus regarding the treatment of renal EWS. Most cases have been treated with surgical resection with adjuvant chemotherapy. The effective chemotherapy agents are vincristine, doxorubicin, ifosfamide, etoposide, actinomycin D and cyclophosphamide. Addition of ifosfamide and etoposide to doxorubicin containing regimens confers a survival advantage in patients with non-metastatic disease [14].

Renal EWS is found in young adults and is characterized by an aggressive clinical course and poor prognosis [9]. Despite aggressive treatment, prognosis remains poor. The median survival for advanced disease is only 2 years [15]. In a retrospective study, 31\% patients had metastasis. The most common site of metastasis was the lung, followed by the liver and bone [9]. The median survival was estimated at 15 months [16].

\section{Conclusion}

Primary EWS should be considered as a differential diagnosis in young individuals presenting with a renal mass. Diagnosis requires histopathology, IHC and cytogenetics. Surgical resection with adjuvant chemotherapy is the treatment of choice. The overall prognosis and survival is poor.

\section{Grant Support}

None.

\section{Financial Disclosure}

None. 


\section{References}

1. Seemayer TA, Thelmo WL, Bolande RP, Wiglesworth FW. Peripheral neuroectodermal tumors. Perspect Pediatr Pathol. 1975;2:151-172.

2. Parham DM, Roloson GJ, Feely M, Green DM, Bridge JA, Beckwith JB. Primary malignant neuroepithelial tumors of the kidney: a clinicopathologic analysis of 146 adult and pediatric cases from the National Wilms' Tumor Study Group Pathology Center. Am J Surg Pathol. 2001;25(2):133-146.

3. Dogra PN, Goel A, Kumar R, Das PK, Gupta SD. Extraosseous Ewing's sarcoma of the kidney. Urol Int. 2002;69(2):150-152.

4. Jimenez RE, Folpe AL, Lapham RL, Ro JY, O'Shea PA, Weiss SW, Amin MB. Primary Ewing's sarcoma/primitive neuroectodermal tumor of the kidney: a clinicopathologic and immunohistochemical analysis of 11 cases. Am J Surg Pathol. 2002;26(3):320-327.

5. Saxena R, Sait S, Mhawech-Fauceglia P. Ewing sarcoma/ primitive neuroectodermal tumor of the kidney: a case report. Diagnosed by immunohistochemistry and molecular analysis. Ann Diagn Pathol. 2006;10(6):363-366.

6. Kang SH, Perle MA, Nonaka D, Zhu H, Chan W, Yang GC. Primary Ewing sarcoma/PNET of the kidney: fineneedle aspiration, histology, and dual color break apart FISH Assay. Diagn Cytopathol. 2007;35(6):353-357.

7. Bing Z, Zhang P, Tomaszewski JE, Maclennan GT. Primary Ewing sarcoma/primitive neuroectodermal tumor of the kidney. J Urol. 2009;181(3):1341-1342.

8. Funahashi Y, Hattori R, Yamamoto T, Mizutani K, Yoshino Y, Matsukawa Y, Sassa N, et al. Ewing's sarcoma / primitive neuroectodermal tumor of the kidney. Aktuelle Urol. 2009;40(4):247-249.
9. Hakky TS, Gonzalvo AA, Lockhart JL, Rodriguez AR. Primary Ewing sarcoma of the kidney: a symptomatic presentation and review of the literature. Ther Adv Urol. 2013;5(3):153-159.

10. Bernstein M, Kovar H, Paulussen M, Randall RL, Schuck A, Teot LA, Juergens H. Ewing's sarcoma family of tumors: current management. Oncologist. 2006;11(5):503519.

11. Friedrichs N, Vorreuther R, Poremba C, Schafer KL, Bocking A, Buettner R, Zhou H. Primitive neuroectodermal tumor (PNET) in the differential diagnosis of malignant kidney tumors. Pathol Res Pract. 2002;198(8):563569.

12. Zucman J, Delattre O, Desmaze C, Plougastel B, Joubert I, Melot T, Peter M, et al. Cloning and characterization of the Ewing's sarcoma and peripheral neuroepithelioma $\mathrm{t}(11 ; 22)$ translocation breakpoints. Genes Chromosomes Cancer. 1992;5(4):271-277.

13. de Alava E, Gerald WL. Molecular biology of the Ewing's sarcoma/primitive neuroectodermal tumor family. J Clin Oncol. 2000;18(1):204-213.

14. Grier HE, Krailo MD, Tarbell NJ, Link MP, Fryer CJ, Pritchard DJ, Gebhardt MC, et al. Addition of ifosfamide and etoposide to standard chemotherapy for Ewing's sarcoma and primitive neuroectodermal tumor of bone. $\mathrm{N}$ Engl J Med. 2003;348(8):694-701.

15. Casella R, Moch H, Rochlitz C, Meier V, Seifert B, Mihatsch MJ, Gasser TC. Metastatic primitive neuroectodermal tumor of the kidney in adults. Eur Urol. 2001;39(5):613-617.

16. Thyavihally YB, Tongaonkar HB, Gupta S, Kurkure PA, Amare P, Muckaden MA, Desai SB. Primitive neuroectodermal tumor of the kidney: a single institute series of 16 patients. Urology. 2008;71(2):292-296. 